\title{
Supplementary Figure S6
}

Scatter plots of the observed association of $7 \mathrm{q} 31$ locus with forearm BMD after condition on the top SNP rs2536189. The P values of SNPs (shown as - $\log 10$ values in y-axis, from the genome-wide single-marker association analysis using the linear regression model) are plotted against their map position (b36) (x-axis).

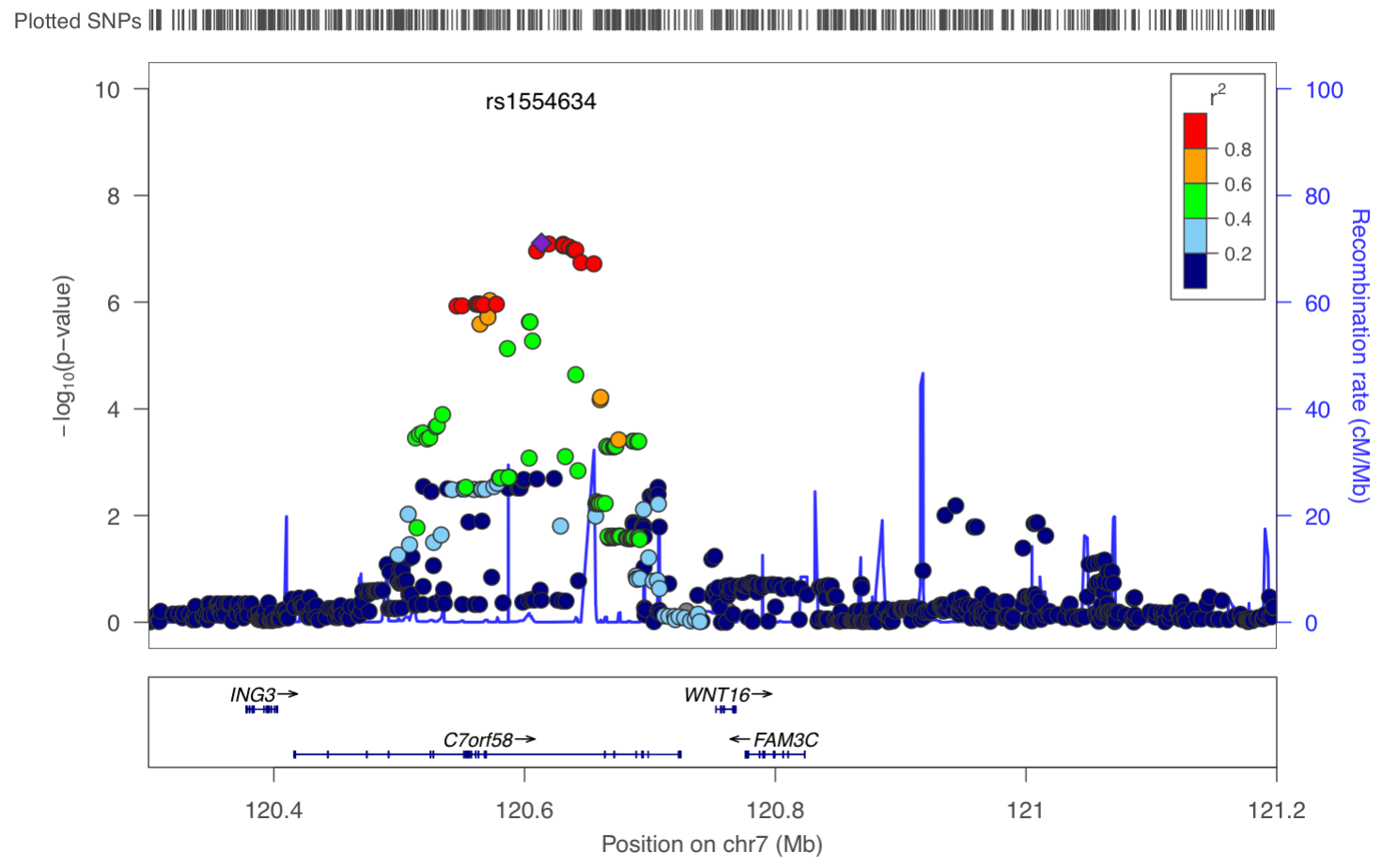

